\title{
TRAÇOS DE "MODERNIDADE" NOS ARTIGOS DE MATEMÁTICA DA REVISTA ESCOLA SECUNDÁRIA
}

\author{
Traces of "modernity" in secondary \\ school journal's mathematical papers
}

\begin{abstract}
Maria Cristina Araújo de Oliveira ${ }^{a}$, Ruy César Pietropaolo ${ }^{b}$
a Doutora em Educação, professora do programa de Pós-Graduação em Educação Matemática da UNIBAN, integra o Grupo de Pesquisas em História da Educação Matemática no Brasil (GHEMAT).São Paulo, SP - Brasil, e-mail: mcrisoliveira6@gmail.com

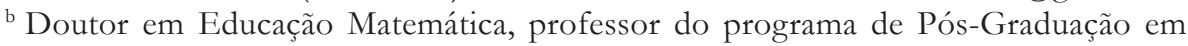
Educação Matemática da UNIBAN, integra o Grupo de Pesquisas em História da Educação Matemática no Brasil (GHEMAT). São Paulo, SP - Brasil, e-mail: rpietropaolo@gmail.com
\end{abstract}

\begin{abstract}
Resumo
Este artigo apresenta uma análise de propostas modernizadoras para o ensino de Matemática, publicadas no período de 1957 a 1963, na Revista Escola Secundária, com vistas ao que posteriormente se configurou como Movimento da Matemática Moderna (MMM). Essa revista foi estruturada como uma instância formadora de professores, pois surge em um contexto em que a grande maioria dos professores brasileiros da escola secundária era autodidata. Nosso objetivo foi identificar conhecimentos matemáticos e pedagógicos que se destacaram como propostas de modernização do ensino dessa disciplina, acompanhando a discussão internacional sobre a modernização do ensino de Matemática no secundário, segundo a perspectiva da apropriação de tais propostas, pelos diferentes autores dos artigos analisados. Uma das propostas modernizadoras identificadas foi a relativização do ensino de geometria dedutiva, priorizando pequenas
\end{abstract}

Rev. Diálogo Educ., Curitiba, v. 8, n. 25, p. 715-726, set./dez. 2008 
demonstrações locais a fim de destacar: as condições admitidas como válidas; o que deve ser demonstrado, chamando a atenção para o que pode ser deduzido das condições admitidas; os raciocínios efetuados para chegar a esses resultados, a partir dos dados e dos conhecimentos já incorporados. Portanto a geometria dedutiva no ginásio deveria ser encarada mais como uma iniciação aos métodos demonstrativos do que propriamente como desenvolvimento de uma teoria. Outro aspecto identificado foi a proposição para o uso de materiais didáticos no ensino de Matemática com a finalidade de proporcionar ao aluno a experimentação e verificação de propriedades e teoremas.

Palavras-chave: História da educação matemática; Revistas pedagógicas; Movimento da Matemática Moderna.

\section{Abstract}

In this paper, we present an analysis of modernising proposals for the teaching of Mathematics, published between 1957 and 1963, in Secondary School Journal, aiming what was later called Modern Mathematics Movement (MMM). This Journal has been structured as a way to training teachers, as it rises when most of secondary school Brazilian teachers were self taught. Our aim is to identify mathematical and pedagogical contents highlighted as such discipline modernising proposals, following an international discussion on modernising mathematics teaching at secondary levels, according to the appropriation perspective of such proposals, by different authors of analysed papers. One of the identified modernising proposals is relativising deductive geometry teaching, priorising small local formal proofs in order to emphasise: assumed conditions as valid; what should be proof, directing the attention to what can be deduced from assumed conditions; performed reasoning to reach the results from data and already grasped knowledge. Therefore deductive geometry in ginásio should be faced more like a start for proof methods than as the development of a theory itself. Other identified aspect is the suggestion of using didactic material in the teaching of Mathematics, in order to make it possible for the student to experiment and verify properties and theorems.

Keywords: History of mathematics education; Pedagogical journals; Modern Mathematics Movement. 
Traços de "modernidade" nos artigos de matemática da revista escola secundária

\section{INTRODUÇÃO}

Este estudo apresenta uma análise de propostas modernizadoras para o ensino de Matemática, publicadas no período de 1957 a 1963, na Revista Escola Secundária, ${ }^{1}$ com vistas ao que posteriormente se configurou como Movimento da Matemática Moderna (MMM).

Nosso objetivo foi identificar conhecimentos matemáticos e pedagógicos que se destacaram como propostas de modernização do ensino dessa disciplina, acompanhando a discussão internacional sobre a modernização do ensino de Matemática no secundário, segundo a perspectiva da apropriação (CERTEAU, 1994; CHARTIER, 1991; CARVALHO, 2006) de tais propostas, pelos diferentes autores dos artigos analisados.

O estudo dos conteúdos dos artigos de revistas pedagógicas possibilita "reconstruir, num momento dado, estágios de funcionamento e estruturação do campo educacional, movimentos de grupos de professores, disputas e atuações" (CATANI; SOUSA, 2001, p. 242-243). Num certo sentido, determinados periódicos educacionais podem ser tomados como "núcleos informativos", caracterizando-se por divulgar um discurso legítimo sobre as questões do ensino e um conjunto de recomendações sobre as formas apropriadas de realizar o trabalho docente.

Segundo Anne-Marie Chartier e Jean Hébrard (apud CATANI; SOUSA, 2001) as revistas pedagógicas permitem acompanhar, continuamente, a "atualidade das preocupações pedagógicas", auxiliando, por exemplo, na compreensão da distância entre a formação idealizada, contida nos textos oficiais, e as realidades resistentes, presentes nas práticas escolares.

Nossa investigação se apóia na noção de apropriação defendida por Chartier (1991, p. 180), que enfatiza a pluralidade de interpretações e usos, bem como a liberdade criadora dos sujeitos em contato com textos, leis e normas. Para Chartier a "apropriação visa uma história social dos usos e das interpretações, referidas a suas determinações fundamentais e inscritas nas práticas específicas que as produzem."

Utilizando-nos das noções de estratégia e tática do historiador Michel de Certeau (1994), que, dito de forma sintética, estabelece a diferenciação entre as práticas relacionadas a um lugar de poder - uma posição de uso no caso das estratégias -, e as práticas relacionadas ou submetidas às práticas de poder, no caso das táticas. Dessa forma, as propostas modernizadoras em nível internacional

A Revista Escola Secundária encontra-se, quase que em sua totalidade, na biblioteca Nadir Kfouri da PUC-SP. Os artigos de matemática e desenho foram, inicialmente, reunidos e catalogados em um volume a partir de fotocópias pela bolsista de iniciação científica PIBIC-CEPE da PUC-SP, Renata Vieira de Oliveira. Um dos produtos desse projeto de iniciação foi a digitalização e a elaboração de um CD-ROM com os artigos de Matemática. Essa Revista circulou, em território nacional, durante o mesmo período em que realizamos nossa análise, de 1957 a 1963.

Rev. Diálogo Educ., Curitiba, v. 8, n. 25, p. 715-726, set./dez. 2008 
se situam no campo das estratégias (CERTEAU, 1994) e os artigos da Revista, nessa perspectiva de análise, no campo das táticas.

Para o desenvolvimento deste trabalho, compartilhamos das idéias de Carvalho (2006, p. 144), considerando que a apropriação "supõe sempre a referência a uma situação particular em que agentes dotados de competências específicas produzem um novo objeto, segundo procedimentos técnicos e regras de uma finalidade condicionada por uma posição.”

\section{A Revista Escola Secundária}

A Campanha de Aperfeiçoamento e Difusão do Ensino Secundário - CADES -, ação governamental desenvolvida pelo Ministério da Educação e Cultura no período de 1953 a 1971, tinha como metas a expansão do ensino secundário em todo o Brasil e a melhoria da qualidade desse ensino, tendo em vista o caráter altamente livresco, abstrato e elitista que marcava os processos de ensino e aprendizagem nas escolas. Assim, uma das finalidades da campanha era ampliar e elevar o nível do ensino secundário, ou seja, "tornar a educação secundária mais ajustada aos interesses e necessidades da época, conferindo ao ensino eficácia e sentido social, bem como criar possibilidades para que os mais jovens tivessem acesso à escola secundária" (BARALDI, 2003, p. 146).

Dentre as diversas atividades desenvolvidas pela CADES está também a publicação da Revista Escola Secundária (de 1957 a 1963), cuja finalidade era a de orientar os professores nos aspectos curriculares, legais e didáticos. $\mathrm{Na}$ primeira edição da Revista, o artigo inicial apresenta o panorama do ensino secundário brasileiro da época e afirma que o intuito da criação da revista era:

Servir de veículo de intercâmbio entre o professorado brasileiro, na troca de idéias, sugestões e experiências, favorecendo a formação de uma nova mentalidade, mais progressista, mais propícia à observação objetiva, à experimentação renovadora e à revisão crítica dos postulados, finalidades, currículos e métodos em que se baseia toda a atuação de nosso magistério. (REVISTA ESCOLA SECUNDÁRIA, 1959, p. 8).

Analisando a Revista Escola Secundária, Fernandes et al. (2006) atribuem a ela a função de levar aos diferentes estados brasileiros, sobretudo aos interiores, os conhecimentos pedagógicos considerados adequados para o desenvolvimento do ensino secundário, bem como divulgar a legislação vigente sobre esse nível de ensino, incluindo comentários sobre sua pertinência e abrangência.

Rev. Diálogo Educ., Curitiba, v. 8, n. 25, p. 715-726, set./dez. 2008 
Traços de "modernidade" nos artigos de matemática da revista escola secundária

Ainda segundo Fernandes et al. (2006) a Revista funcionou como veículo de legitimação das ações da Diretoria de Ensino Secundário do Ministério da Educação e Cultura (DESE-MEC), informando sobre os programas de qualificação docente do MEC, justificando sua realização e sugerindo a adesão dos professores e das escolas, tanto públicas quanto particulares, ao Programa das Classes Secundárias Experimentais. Por meio desse Programa, o Ministério da Educação estimulou a experimentação de novas propostas e modelos pedagógicos a serem testados e avaliados no ensino secundário.

Pode-se, em síntese, afirmar que a revista foi estruturada como uma instância formadora de professores, uma vez que a CADES surgiu em um contexto em que a grande maioria dos professores brasileiros desse segmento de ensino era autodidata: em 1957, apenas $16 \%{ }^{2}$ dos professores em atuação eram licenciados pelas Faculdades de Filosofia.

\section{Propostas internacionais de modernização da matemática do ensino secundário}

Dois encontros internacionais são determinantes na formação e divulgação do ideário do movimento de modernização da Matemática, conhecido como MMM. O primeiro deles, o Seminário de Royaumont, realizado em 1959, no Cercle Culturel de Royaumont, em Asnières-sur-Oise, França, reuniu em torno de 50 representantes de 18 países e é considerado um marco para o Movimento da Matemática Moderna. O segundo foi o encontro de Dubrovnik, realizado em 1960, do qual emergem orientações sobre o ensino de Matemática no secundário tanto com relação a conteúdos matemáticos quanto com relação aos métodos de ensino de tais conteúdos.

Tais orientações foram sistematizadas no livro Un programme moderne de mathématiques por l'enseignement sécondaires, publicado pela $\mathrm{OECD}^{3}$ em 1961, traduzido para o português pelo professor Jacy Monteiro (GEEM). ${ }^{4}$

A partir de então, as novas propostas para o ensino de Matemática apresentam um programa influenciado por idéias estruturalistas dominantes na época, que, com relação aos conteúdos Matemáticos, revelam a influência da concepção bourbakista ${ }^{5}$ e quanto aos métodos, os estudos de Jean Piaget.

2 Tal índice integra o texto de apresentação da Revista Escola Secundária n. 1, 1959, p. 8. A assinatura ao final do texto é: A Redação.

Organização para Cooperação Econômica e Desenvolvimento.

4 Grupo de Estudos do Ensino da Matemática.

5 Em síntese a concepção bourbakista da matemática consiste em apresentá-la destacando sua unidade, suas estruturas e o método axiomático.

Rev. Diálogo Educ., Curitiba, v. 8, n. 25, p. 715-726, set./dez. 2008 
De forma bastante sintética, podemos dizer que, quanto aos conteúdos curriculares, destacam-se três orientações: dar ênfase à unidade da matemática, introduzir novos tópicos considerados modernos, relacionados especialmente às estruturas Matemáticas e ter como meta trabalhar segundo o método axiomático.

Quanto aos métodos, as orientações se referem ao processo de ensino e de aprendizagem, e aos papéis do professor e do aluno. Entre as recomendações estão as valorizações: da compreensão em detrimento à mecanização, da aprendizagem por descoberta, da intuição como algo que deve preceder ao ensino dedutivo. Também se destaca a importância dada ao trabalho experimental como uma etapa anterior à abstração (GUIMARÃES, 2007).

\section{Propostas modernizadoras para o ensino de matemática na Revista Escola Secundária}

Com relação à introdução de novos conteúdos no ensino de matemática do secundário, o principal artigo é de autoria do professor Osvaldo Sangiorgi. No artigo de título Ainda Geometria Euclidiana para os atuais ginasianos?, publicado em 1960, o autor faz uma defesa do ensino de Geometrias não Euclidianas para o ginásio: “[...] a Geometria Lobatchewskiana, assim como outras, deve ser apresentada aos nossos estudantes como propiciadora de novos hábitos de pensar, uma vez que eles já se 'acostumaram' a ver apenas unilateralmente importantes proposições" (SANGIORGI, 1960, p. 78).

Nesse mesmo artigo, para justificar a necessidade da introdução de uma nova Geometria para os alunos do ginásio, Sangiorgi baseia seus argumentos nos avanços da Geometria numa perspectiva do formalismo, com os trabalhos de Pasch, Peano e Hilbert, entre outros. Também destaca a importância da Geometria Riemanniana para o desenvolvimento da Física Moderna.

Sangiorgi considera ao defender a Geometria Lobatchewskiana que ela é filosoficamente honesta, pioneira nos modernos conceitos matemáticos e "digna da máxima reflexão no que concerne à Didática da Matemática" (SANGIORGI, 1960, p. 79). A fim de respaldar, didaticamente, o ensino de Geometrias não Euclidianas aos alunos do ginásio, este autor se baseia em estudos de Jean Piaget, quanto ao caráter topológico dos conceitos geométricos na infância, citando também estudos do pedagogo Gattegno, a respeito do interesse do geral sobre o particular para alunos com mais de 12 anos.

No artigo de Sangiorgi existe também referência a uma publicação italiana que apresenta a Geometria "ordinária” como caso particular, introduzindo os teoremas fundamentais no plano e no espaço, independentes do postulado Euclidiano das paralelas.

Rev. Diálogo Educ., Curitiba, v. 8, n. 25, p. 715-726, set./dez. 2008 
Traços de "modernidade" nos artigos de matemática da revista escola secundária

Sobre a geometria, que figura entre os conteúdos que constituem maiores dificuldades em relação ao ensino e à aprendizagem, desde o início do século XX, ${ }^{6}$ alguns artigos discutem a necessidade de se trabalhar nas séries iniciais do secundário numa perspectiva intuitiva como etapa necessária para o desenvolvimento da geometria dedutiva nas séries finais. A passagem da intuição para a dedução é uma das propostas veiculadas no ideário do MMM com relação aos métodos de ensino.

Essa mesma preocupação se evidencia no artigo da professora Martha Blauth Menezes, $O$ ensino da geometria dedutiva na escola secundária, publicado em 1959, destacando a importância da geometria intuitiva, do uso de materiais e da realização de medidas com instrumentos na preparação para a geometria dedutiva. Amparando-se nos estudos de psicologia, que discutem as possibilidades do adolescente compreender o processo de dedução, a autora exemplifica um método didático que consiste em apresentar um teorema fundamental aceito como postulado e teoremas que decorrem deste e que podem ser demonstrados a partir dele. Esse método se baseia em uma proposição do professor Antonio Rodrigues.

Nesse artigo, Menezes analisa uma experiência de aplicação dessa metodologia, realizada em duas turmas diferentes do Colégio de Aplicação da Faculdade de Filosofia da UFRGS ${ }^{7}$ durante dois semestres letivos, que compreenderam uma trajetória composta de três etapas: geometria intuitiva, introdução à geometria dedutiva e geometria dedutiva. O resultado mais importante dessa experiência, segundo a professora, foi que a maior parte dos alunos adquiriu um pensamento lógico e um acentuado gosto pela geometria dedutiva (REVISTA ESCOLA SECUNDÁRIA, 1959, p. 77).

É importante destacar que no II Congresso Brasileiro do Ensino de Matemática, realizado em 1957, em Porto Alegre, os professores Antonio Rodrigues e Martha Blauth Menezes já haviam apresentado uma tese composta por dois capítulos, discutindo o ensino de geometria dedutiva.

Em artigo do volume 7 da Revista Escola Secundária, Rodrigues diminui, de certa forma, a importância do ensino da geometria dedutiva. Ele considera que quaisquer que sejam os conceitos geométricos desenvolvidos em sala de aula não deveria haver, por parte do professor, preocupação excessiva com o rigor, apesar de sua indicação de que esse estudo deveria contemplar algum nível de formalidade. Ele parecia adotar o princípio de que o ensino das demonstrações deveria ter menos ênfase tendo em vista que o programa de rigor euclidiano fora relativizado, historicamente, nas demonstrações em outros campos.

6 Pode-se notar a preocupação de Euclides Roxo em seu livro Curso de Matemática Elementar, publicado em 1929, com a apresentação de conceitos geométricos de maneira intuitiva.

Universidade Federal do Rio Grande do Sul.

Rev. Diálogo Educ., Curitiba, v. 8, n. 25, p. 715-726, set./dez. 2008 
Esse autor também alerta que, para o professor minimizar as dificuldades do processo de ensino e aprendizagem da geometria, que era apresentada fundamentalmente pela via dedutiva, dever-se-ia inicialmente organizar uma lista de axiomas, incluindo teoremas de "demonstração intuitiva", para depois "selecionar um conjunto de teoremas fundamentais e suas consequências principais de modo que constituam um ótimo material para o treinamento do aluno nas demonstrações" (REVISTA ESCOLA SECUNDÁRIA, 1959, p. 65). Portanto, nesse artigo, leva-se em conta que a geometria dedutiva no ginásio deve ser encarada mais como uma iniciação aos métodos demonstrativos do que propriamente como desenvolvimento de uma teoria.

Assim, segundo as indicações de Rodrigues, o processo de ensino e aprendizagem da Geometria deveria permitir que se realizasse o que mais tarde alguns documentos de implementação da Matemática Moderna ${ }^{8}$ denominariam de pequenas "demonstrações locais" a fim de destacar: as condições admitidas como válidas; o que deve ser demonstrado, chamando a atenção para o que pode ser deduzido das condições admitidas; os raciocínios efetuados para chegar a esses resultados, a partir dos dados e dos conhecimentos já incorporados.

Desse modo, dar-se-ia uma idéia do método axiomático, pois as condições admitidas seriam os axiomas da teoria, os resultados seriam os teoremas e as "demonstrações locais" forneceriam o exemplo de aplicação do método dedutivo. Levar em conta esse princípio era sem dúvida introduzir uma inovação no currículo de matemática.

A Revista Escola Secundária também contém, em todos os seus volumes, pelo menos um artigo sobre Desenho. Naquela época Desenho e Matemática constituíam disciplinas distintas. O último artigo sobre Desenho publicado na Revista Escola Secundária, em 1963, assume uma posição bastante diferente dos demais. Discute um conteúdo que, segundo o autor, era pouco trabalhado por ser planejado para o final do curso ginasial - a equivalência de áreas. O autor critica as aulas de desenho geométrico em que o conteúdo é trabalhado por meio de "receitas" e avalia que a falta de motivação dos alunos se deve ao fato de que não lhes são apresentados os porquês. Em seu texto ele justifica as construções realizadas nos problemas de equivalência, com base nos conceitos matemáticos sobre o cálculo de áreas. Os argumentos utilizados pelo autor se baseiam nas novas idéias que começavam a circular entre os professores de Matemática, com o denominado Movimento da Matemática Moderna.

8 Subsídios para implementação dos Guias Curriculares de Matemática, elaborado pela Coordenadoria de Estudos e Normas Pedagógicas - CENP - da Secretaria de Estado da Educação de São Paulo, em 1976.

Rev. Diálogo Educ., Curitiba, v. 8, n. 25, p. 715-726, set./dez. 2008 
Traços de "modernidade" nos artigos de matemática da revista escola secundária

Um dos aspectos defendidos pela proposta modernizadora da Matemática Moderna com relação aos métodos de ensino era a experimentação ou a aprendizagem pela descoberta. Ao longo dos volumes da Revista Escola Secundária são publicados artigos que discutem o uso de materiais didáticos e o laboratório de Matemática.

$\mathrm{O}$ artigo O Material didático no ensino da Matemática, publicado em 1958, volume 6, de Manuel Jairo Bezerra discute a importância do uso de "acessórios de ensino" ou materiais didáticos, particularmente no ensino de geometria intuitiva. Apresenta um panorama dos materiais didáticos existentes, divididos em categorias identificadas pelas diferentes finalidades. Por exemplo, os materiais didáticos informativos dizem respeito aos livros, revistas e outros textos impressos. Na categoria dos materiais experimentais ou demonstrativos, os jogos aritméticos, o ábaco, aparelhos para a geração de sólidos, entre outros.

O professor também apresenta a idéia dos laboratórios de Matemática e destaca que nos Estados Unidos a existência de tais laboratórios não é exceção nas escolas. Analisa as dificuldades existentes no Brasil em relação aos laboratórios e aos materiais didáticos, mas relata experiências de professores que vão aos poucos elaborando, junto com seus alunos, alguns materiais de baixo custo, que podem auxiliar na aprendizagem.

Em 1961, o professor Manuel Jairo Bezerra relata, num outro artigo, volume 17, a exposição de materiais didáticos por ele organizada, com a participação de vários outros professores. Além de apresentar as conquistas dos professores e escolas envolvidas na atividade com a produção dos materiais, há uma lista dos materiais expostos.

A esse respeito, podemos citar também o artigo O Método do Laboratório em Matemática de Malba Tahan, ${ }^{9}$ publicado em 1963 no volume 19. Neste artigo são indicados e descritos os materiais que deveriam compor o laboratório. Além disso, são sugeridas algumas atividades como: fundação de um clube de matemática, publicação de um boletim mensal, conferências, etc. O professor Tahan também evidencia em seu texto falas de algumas personalidades que defendem o uso de materiais concretos no ensino de Matemática, como a de Rui Barbosa a respeito da importância da "Taquimetria de Lagout" - o único método que permite ensinar geometria e demonstrar os teoremas "às inteligências mais rudimentares" (TAHAN, 1963, p. 78). Do mesmo modo, apresenta a defesa de Euclides Roxo, emérito educador matemático brasileiro, a respeito "das excelências" do Laboratório, por permitir a "self-discovery", que seria uma possível maneira de auxiliar o estudante "a galgar a íngreme rampa da abstração matemática" (TAHAN, 1963, p. 79).

9 Malba Tahan era o pseudônimo utilizado pelo professor Júlio César de Mello e Sousa que foi catedrático do Colégio Pedro II, renomado autor de livros didáticos, na primeira metade do século passado. Assinando como Malba Tahan, ficou conhecido, sobretudo pelo seu livro O homem que calculava, que foi traduzido em várias línguas.

Rev. Diálogo Educ., Curitiba, v. 8, n. 25, p. 715-726, set./dez. 2008 
Tahan também enumera vantagens do Laboratório para ensinar Matemática tais como: levar os alunos a fazerem descobertas; levar à aprendizagem os alunos menos dotados; motivar alunos e professores. Todavia, o autor apresenta as desvantagens do método: levar o aluno a aceitar, como rigorosas, certas demonstrações experimentais e grosseiras; levar o aluno a fugir das abstrações e procurar recursos materiais para as demonstrações matemáticas; ser muito dispendioso; exigir muito tempo, sob o risco de não ser cumprido o programa; exigir muito preparo do professor; não poder ser aplicado a todos os pontos do programa.

Dois outros artigos tratam da utilização de materiais didáticos no ensino de Matemática. Um deles, publicado no volume 10, descreve como deve ser confeccionado um material para fazer a experimentação do teorema de Pitágoras com base na demonstração de Euclides, conforme figura a seguir.

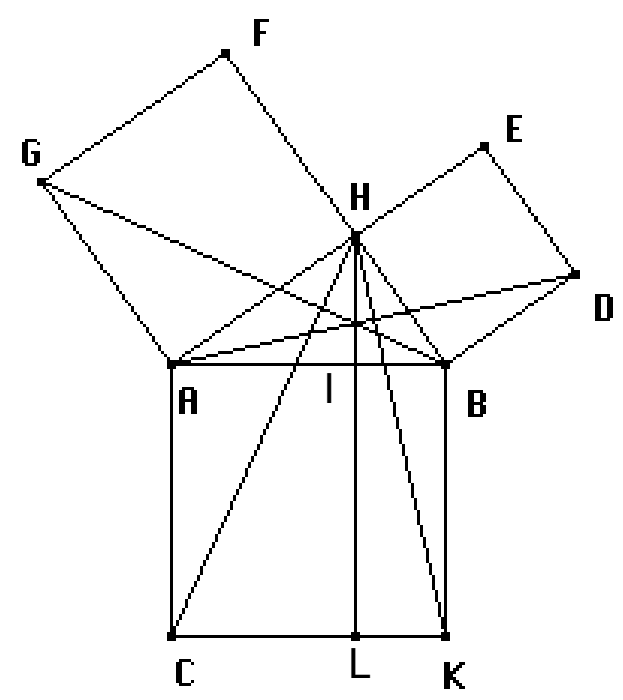

Esse artigo também traz a descrição de como fabricar um material para ensinar segmentos, linhas poligonais e polígonos. $\mathrm{O}$ autor comenta os bons resultados obtidos com seus alunos utilizando esses materiais.

Num outro artigo, volume 17, uma professora relata, com entusiasmo, sua experiência em propor aos alunos a verificação experimental de teoremas. Destaca que a produção dos materiais foi feita pelos alunos que ficaram bastante motivados com essa metodologia. A professora ressalta a preocupação em mesclar a experimentação com a dedução na demonstração de teoremas.

Rev. Diálogo Educ., Curitiba, v. 8, n. 25, p. 715-726, set./dez. 2008 
Traços de "modernidade" nos artigos de matemática da revista escola secundária

\section{CONSIDERAÇÕES FINAIS}

Identificamos nessa análise da Revista Escola Secundária artigos - poucos - que procuraram se apropriar de princípios que norteavam o MMM, em especial os que se referem às inovações curriculares como a indicação de novos conteúdos e mudanças nos métodos de ensinar. Em relação às sugestões de introduções de novos temas as encontramos somente em um artigo: nele, são discutidas as possibilidades de desenvolver, já no ginásio, outras geometrias que não as euclidianas.

Quanto ao ensino das demonstrações existem diversas recomendações de relativização nas escolas secundárias, ou seja, a escola deveria dar apenas uma idéia do método axiomático. Caberia aos professores organizar e selecionar os teoremas admitidos como verdadeiros que constituiriam, assim, os axiomas da teoria, e, portanto, os resultados seriam os teoremas e as "demonstrações locais" forneceriam exemplos de aplicação do método dedutivo.

Outro aspecto identificado foi a proposição para o uso de materiais didáticos no ensino de Matemática com a finalidade de proporcionar ao aluno a experimentação e verificação de propriedades e teoremas.

Estas recomendações seriam a apropriação, pelos autores desses artigos, do ideário do Movimento da Matemática Moderna que preconizava que os conteúdos tradicionais e a arcaica metodologia utilizada no ensino da Matemática não favoreciam uma aprendizagem satisfatória.

\section{REFERÊNCIAS}

BARALDI, I. M. Retraços da educação matemática na região de Bauru (SP): uma história em construção. 2003. 240 f. Tese (Doutorado em Educação Matemática) - Instituto de Geociências e Ciências Exatas, Rio Claro, SP, 2003.

CARVALHO, M. M. C. Livros e revistas para professores: configuração material do impresso e circulação internacional de modelos pedagógicos. In: PINTASSILGO, J. et al. (Ed.). História da escola em Portugal e no Brasil: circulação e apropriação de modelos culturais. Lisboa: Colibri, 2006. p. 141-173.

CATANI, D. B.; SOUZA, C. P. A geração de instrumentos de pesquisa em história da educação: estudos sobre revistas de ensino. In: VIDAL, D. G.; HILSDORF, M. L. S. (Org.). Brasil 500 anos: tópicos em história da educação. São Paulo: Universidade de São Paulo, 2001. p. 241-254.

CERTEAU, M. D. A invenção do cotidiano. Petrópolis, RJ: Vozes, 1994.

Rev. Diálogo Educ., Curitiba, v. 8, n. 25, p. 715-726, set./dez. 2008 
CHARTIER, R. O mundo como representação. Estudos avançados, São Paulo, v. 11, n. 5, p. 173-191, 1991.

FERNANDES, A. L. C. et al. Aspectos da imprensa periódica educacional em Lisboa e no Rio de Janeiro (1921-1963). In: CONGRESSO LUSO-BRASILEIRO DE HISTÓRIA DA EDUCAÇÃO, 6., 2006, Rio de Janeiro. Anais... Rio de Janeiro: [s.n.], 2006. p. 44-54.

GUIMARÃES, H. Por uma matemática nova nas escolas secundárias perspectivas e orientações curriculares da Matemática Moderna. In: MATOS, J. M.; VALENTE, W. R. (Org.). A matemática moderna nas escolas do Brasil e de Portugal: primeiros estudos. São Paulo: Da Vinci, 2007. p. 21-45.

REVISTA ESCOLA SECUNDÁRIA. Rio de Janeiro: Campanha de Aperfeiçoamento e Difusão do Ensino Secundário, v. 1-19, 1959.

ROXO, E. Curso de matemática elementar. Rio de Janeiro: Francisco Alves, 1929. v. 1.

SANGIORGI, O. Ainda geometria Euclidiana para os atuais ginasianos? Revista Escola Secundária, [S. 1.], v. 13, p. 77-81, 1960.

SÃO PAULO. Secretaria da Educação. Centro de Recursos Humanos e Pesquisas Educacionais "Prof. Laerte Ramos de Carvalho". Guias curriculares propostos para as matérias do núcleo comum do ensino do 1. ${ }^{\circ}$ grau. São Paulo, SE/CERHUPE, 1976.

Coordenadoria de estudos e normas pedagógicas. Subsídios para a implementação do guia curricular de matemática: geometria para o $1^{\circ}$. Grau. $1^{\text {a }}$ a $8^{\mathrm{a}}$ Séries. São Paulo: Se/CENP, 1977. (Volume do professor e do aluno).

TAHAN, M. O método do laboratório em matemática. Revista Escola Secundária, v. 19, p. 71-80, 1963.

Recebido: 18/06/2008

Received: 06/18/2008

Aprovado: 01/07/2008

Approved: 07/01/2008

Rev. Diálogo Educ., Curitiba, v. 8, n. 25, p. 715-726, set./dez. 2008 